\title{
Salivary cytokines in children with nephrotic syndrome versus healthy children: a comparative study
}

David Pollak

Hebrew University of Jerusalem Faculty of Medicine

Yael Borovitz

Schneider Children's Medical Center of Israel

Dana Levy

Hebrew University of Jerusalem Faculty of Medicine

Yehuda Klein

Hebrew University of Jerusalem Faculty of Medicine

Nathalie Bernfeld

Hebrew University of Jerusalem Faculty of Medicine

Miriam Davidovits

Schneider Children's Medical Center of Israel

Esti Davidovich ( $\nabla$ esti@dr-st.co.il )

Hebrew University Hadassah Medical School https://orcid.org/0000-0003-0183-9337

\section{Research article}

Keywords: saliva, nephrotic syndrome, diagnostics, pediatric patients, cytokines, inflammation

Posted Date: April 9th, 2020

DOI: https://doi.org/10.21203/rs.3.rs-19893/v1

License: (c) (i) This work is licensed under a Creative Commons Attribution 4.0 International License. Read Full License

Version of Record: A version of this preprint was published at Journal of Clinical Medicine on August 20th, 2020. See the published version at https://doi.org/10.3390/jcm9092691. 


\section{Abstract}

Background: The aims of this study were to compare salivary cytokines and total protein, between children with nephrotic syndrome and healthy children; and to examine whether saliva parameters can differentiate between steroid sensitivity and resistance, and between disease remission and relapse.

Methods: Twenty-seven children with nephrotic syndrome were classified according to steroid sensitivity and resistance, and disease remission and relapse. Twenty healthy children served as controls. Whole saliva samples were collected from all the participants. Urine and blood tests done on the same day as the saliva collection were recorded. Salivary total protein was quantified using bicinchoninic acid; and IFNy, IL-4, IL-8, IL-6 and IL1 $\beta$ levels using ELISA.

Results: The mean ages of the nephrotic syndrome and control groups were $11.3 \pm 2.4$ and $9 \pm 4.2$, respectively. Compared to the control group, for the nephrotic syndrome group, total salivary protein was significantly lower; as were the levels of all the cytokines examined except IFNy. Statistically significant differences were not found in any of the salivary markers examined, between the children with nephrotic syndrome who were treatment sensitive $(n=19)$ and resistant $(n=8)$. Protein and IL-8 salivary levels were lower in the active $(n=7)$ than in the remission ( $n=20)$ group.

Conclusions: Salivary parameters distinguished children with nephrotic syndrome in relapse from healthy children. This may be due to decreased salivary protein excretion, which reflects decreased plasma levels, consequent to proteinuria. Accordingly, salivary markers may be developed as a diagnostic or screening tool for NS activity.

\section{Background}

Nephrotic syndrome (NS) is the most common glomerular disease in children, and is manifested by massive proteinuria. The consequent decrease in circulating albumin level leads to severe reduction in oncotic pressure and generalized edema [1, 2]. The proteinuria in NS stems from loss of size and charge selectivity of the glomerular basement membrane, due to activated T-lymphocytes that are mediated by circulating factors. This impairs the function of the glomerular filtration barrier [2] and results in secretion of proteins into the urine [1, 2]. Urinary loss of protein causes other complications of NS, such as infections, hyperlipidemia and hypercoagulability [1, 2].

Minimal change nephrotic syndrome (MCNS) is the most common type of NS in childhood. MCNS responds well to steroid treatment; and the prognosis of long-term kidney function is good. Yet, MCNS has a high relapse rate (70-80\%). The protocol for treatment of the first episode generally includes 4-6 weeks of high dose steroids, $60 \mathrm{mg} / \mathrm{m}^{2}$ daily; and then $40 \mathrm{mg} / \mathrm{m}^{2}$ on alternate days for an additional 4 weeks; followed by gradually tapering down [3]. Most cases of MCNS remit (negative protein on urinalysis for three consecutive days [3]) within 4 weeks' treatment. Non-responsive cases (about 7-8\%) are defined as steroid-resistant NS (SRNS) and include histopathological types of kidney diseases other than MCNS [3].

It is unclear whether the capillary permeability in NS is limited to the kidney or affects other capillary systems such as salivary glands, which secrete the oral fluids. The complex proteome of these oral fluids comprise 2340 identified proteins [4]. These proteins are derived from salivary gland secretions, plasma filtrates, cellular and bacterial derivatives, bronchial and gastrointestinal fluids and others. Interest has grown in investigating possible applications of oral fluids in the diagnosis of systemic, as well as oral diseases. Indeed, previous studies detected biomarkers in oral fluids for lung [5], breast [6] and oral cancers [7], diabetes [8], and autoimmune disorders [9].

Following from the above, salivary protein secretion in NS may reflect changes in systemic capillary permeability and changes in plasma protein levels. Thus, the current study aimed to evaluate salivary total protein and cytokine secretion in children with NS, compared to healthy controls. In addition, we examined differences in salivary markers between (steroid-sensitive nephrotic syndrome) SSNS and SRNS, and also between those in remission versus the active state.

\section{Methods}

\section{Study population}

Children with NS were recruited at the Institute of Pediatric Nephrology at Schneider Children's Medical Center, Petach Tikva, Israel. The study was approved by the local Helsinki committee (Rabin Medical Center) and the Israel Ministry of Health (0466-12-RMC). The participants were categorized according to their treatment response (SSNS and SRNS), and according to whether their disease was in remittance or in the active state. During a routine visit at the clinic, the children were asked to spit into a collection tube for 5 minutes (unstimulated saliva). When urine and blood tests were done on the same day as the saliva collection, these were recorded.

Healthy children without a history of impaired renal function or proteinuria served as a control group, and were recruited at the Department of Pediatric Dentistry at the Hebrew University - Hadassah School of Dental Medicine in Jerusalem, Israel.

\section{Saliva collection}

Saliva was collected in a quiet room between $8 \mathrm{AM}$ and 12:30 PM. The participants refrained from eating, brushing their teeth or rinsing with mouthwash for at least 1 hour before spitting. The collected saliva was kept at $-80{ }^{\circ} \mathrm{C}$ until analysis.

Page 2/8 


\section{Total salivary protein quantification}

Saliva samples were diluted $\mathrm{x} 10$ in double distilled water. Protein concentration was measured using the bicinchoninic acid (BCA) protein assay kit (Thermo Fisher Scientific, Waltham, MA), according to the manufacturer's instructions.

\section{Salivary cytokine quantification}

Salivary levels of human IFNy, IL-4, IL-8, IL-6 and IL $1 \beta$ were measured using ELISA kits according to manufacturer instructions (R\&D systems, Minneapolis, MN, US).

\section{Statistical analysis}

Differences between values of the saliva parameters in the NS and control groups were examined using the Student

sTtest. Bl $\infty$ dtestvalues $\in$ NSgroupwerecompared $\rightarrow$ s tandardmeanvaluesof $\chi$ ldrenofthesamea $\geq$ and sexu sin gtheStudent $\mathrm{s} \mathrm{T}$ test. Statistical significance was set at $0.05 \mathrm{P}$ value.

\section{Results}

The study included 27 pediatric patients diagnosed with NS and 20 healthy children as controls. In the NS group, 19 were SSNS and 8 were steroid resistant SRNS. Seven of the participants with NS had full-blown (active) disease at the time of saliva collection and 20 were in remission, with normal urinary protein excretion.

The mean ages of the healthy and NS groups were $11.3 \pm 2.4$ and $9 \pm 4.2$, respectively. The respective proportions of females were $30 \%$ ( $6 / 20)$ and $52 \%$ $(14 / 27)$ (Table 1). No statistically significant differences were found in the mean age and the gender distribution between the SSNS and the SRNS groups (Table 2). Table 3 describes the demographic and clinical characteristics of children with nephrotic syndrome according to participants with remission and relapse.

Table 1

\begin{tabular}{|llll|}
\hline Variable & Healthy & Nephrotic syndrome & P value \\
\hline Number of children & 20 & 26 & \\
\hline Age & $11.9 \pm 2.5$ & $9.1 \pm 4.3$ & 0.007 \\
Gender (\% of Female) & 29 & 50 & n.s. \\
\hline
\end{tabular}

Table 2

Demographic and clinical characteristics of children with nephrotic syndrome according to steroid-resistant nephrotic syndrome (SRNS) and steroid-sensitive nephrotic syndrome (SSNS)

\begin{tabular}{|llll|}
\hline Variable & SRNS & SSNS & P value \\
\hline Number of children & 7 & 19 & \\
\hline Mean age, years & $9.9 \pm 5.5$ & $8.8 \pm 3.9$ & n.s. \\
\hline Gender (female) & $4(57 \%)$ & $10(53 \%)$ & n.s. \\
\hline Positive for stick urine protein & $7(100 \%)$ & $3(15 \%)$ & $<0.001$ \\
\hline Protein/creatinine ratio & $5.1 \pm 4.5$ & $2.3 \pm 3.7$ & n.s. \\
\hline Plasma albumin & $3.2 \pm 0.6$ & $3.3 \pm 1.2$ & n.s. \\
\hline Plasma creatinine & $0.8 \pm 0.5$ & $0.4 \pm 0.1$ & n.s. \\
\hline Data are presented as number (\%) or mean \pm standard deviation \\
\hline
\end{tabular}


Table 3

Demographic and clinical characteristics of children with nephrotic syndrome according to participants with remission and relapse

\begin{tabular}{|lccl|}
\hline Variable & Remission & Relapse & P value \\
\hline Number of children & 16 & 10 & \\
\hline Mean age, years & $9 \pm 4$ & $9.3 \pm 4.9$ & n.s. \\
\hline Gender (female) & $9(56)$ & $4(40)$ & n.s. \\
\hline Protein/creatinine ratio & $0.1 \pm 0$ & $4.7 \pm 3.9$ & 0.003 \\
\hline Plasma albumin & $4 \pm 0.9$ & $2.9 \pm 0.7$ & 0.04 \\
\hline Plasma creatinine & $0.4 \pm 0.1$ & $0.7 \pm 0.5$ & n.s. \\
\hline Data are presented as number (\%) or mean \pm standard deviation \\
\hline
\end{tabular}

The mean salivary total protein levels were significantly lower in the NS group than in the control group, $374.9 \mathrm{pg} / \mathrm{ml} \mathrm{vs}$. $479.7 \mathrm{pg} / \mathrm{ml}(\mathrm{P}<0.05)$. Mean salivary protein levels were lower in both the SRNS and SSNS groups than in the control group (Fig. 1, P $<0.05$ for healthy vs. SSNS). The mean salivary protein level was lower in the relapse than the remission group $(\mathrm{P}<0.05)$; this corresponded with the abnormal urinary protein excretion observed.

Mean levels of the inflammatory markers examined were lower in the NS group than in the control group: $1136.23 \mathrm{pg} / \mathrm{ml}$ vs. $1913.89 \mathrm{pg} / \mathrm{ml}$ for IL-8 ( $<<$ 0.05 , Fig. 2) and $124.04 \mathrm{pg} / \mathrm{ml}$ vs. $199.02 \mathrm{pg} / \mathrm{ml}$ for IL-6 (Fig. 2). Stratifying the results according to remission and relapse states did not show statistically significant differences, though the mean IL-8 level was lower in the relapse than the remission group (Fig. 2). Mean levels of IL1 $\beta$, IFNy and IL-4 were similar in the healthy, SRNS and SSNS groups (Fig. 3). Likewise, the levels of these cytokines were similar in the remission and relapse groups (Fig. 3).

\section{Discussion}

The current study provides evidence that oral fluids reflect systemic changes that accompany NS; and highlights the potential use of saliva as a biofluid for systemic monitoring. Furthermore, the results show a unique inflammatory pattern in children with NS, characterized by low salivary IL-8. However, this pattern does not clearly differentiate between remission and relapse states.

While the main characteristic of NS is significant proteinuria and a general decrease in circulating plasma proteins, its impact on capillary permeability in various organs, such as the salivary gland, is unknown. In the current cohort of children with NS, saliva showed a similar pattern to serum, with lower protein levels, especially in the relapse state. Therefore, despite the increased permeability of the glomerular filter in NS, capillary permeability of the salivary gland appears to be unaffected. Decreased serum protein levels correlate with changes in saliva composition that are evident in other diseases $[10,11]$, and corroborate the intimate relation between serum and saliva characteristics. Furthermore, similar correlations have been shown between saliva and systemic markers for various conditions such as diabetes [8] and autoimmune disorders [9] in adults. In children, changes in salivary markers have also been shown for various conditions, such as autistic spectrum disorder [12], Down Syndrome [13], pertussis [14], pneumonia [15] and asthma [16].

Children with NS are prone to infections due to a loss in immune system factors such as immunoglobulins in the urine [17]. Furthermore, the steroidal treatment that is administered as an immune suppressive may impair general and oral health. The current study supports these premises, and showed reduced inflammatory markers (IL-6 and IL-8) in children with NS versus healthy children. Similarly, in their cohort of children with NS, Guimarães et al. found low levels of systemic inflammatory markers including circulating B lymphocytes, NK and NKT cells [18].

A possible etiology of NS is abnormalities in the immune system, either in the humoral or cellular arms [19]. This is based on a number of observations. One is the sensitivity of most forms of primary NS to inhibitors of T lymphocyte: mycophenolate mofetil, corticosteroids, calcineurin inhibitors and alkylating agents. Second is the frequent occurrence of measles and malaria, following remission of NS, both of which are diseases that impair cellmediated immunity. Third is the detection of MCNS as a paraneoplastic manifestation of lymphoreticular malignancies and other Hodgkin's disease. Furthermore, depressed cell-mediated immunity has been observed during relapses of MCNS. This has been shown in conjunction with alterations in T cell subsets and increased cell surface expression of IL-2 receptors on T cells, reflective of T cell activation [20,21]. In a transcriptome analysis of SRNS vs. SSNS, Gyung Kang et al. recently showed a significant difference in the IL-4 pathways of mononuclear cells [22]. However, the current study did not find a difference in salivary IL-4 between the two groups. This discrepancy may be explained by the participation of immune cells other than mononuclear cells, in saliva cytokine secretion. Furthermore, Gyung Kang et al. found that the differences in these pathways are associated with IL-4 receptors, and not with the cytokine itself.

\section{Conclusions}


The current study shows that saliva is a potential alternative to serum markers for NS monitoring. The tested inflammatory cytokines mirrored, in part, the systemic inflammatory physiology of the participating children. However, the cytokines examined were unable to differentiate between steroid resistance and steroid sensitivity, nor between the relapse and remission states. On the other hand, our findings regarding whole salivary protein levels raise the possibility of differentiating between the remission and relapse states. Further studies should investigate the use of saliva as a bio-fluid to monitor the systemic health of persons with NS, and also in other conditions, in both pediatric and adult populations.

\section{Abbreviations}

NS, nephrotic syndrome; MCNS, minimal change nephrotic syndrome; SRNS, steroid-resistant nephrotic syndrome; SSNS, steroid-sensitive nephrotic syndrome

\section{Declarations}

\section{Ethics approval and consent to participate:}

The study was approved by the local Helsinki committee (Rabin Medical Center) and the Israeli Ministry of Health (0466-12-RMC). All the participants and / or their parents signed informed consent before test were taken, according to approval of the Institutional Review Board.

\section{Consent for publication:}

Not relevant

\section{Availability of data and material:}

The datasets used and/or analysed during the current study are available from the corresponding author on reasonable request.

\section{Competing interests:}

The authors declare that they have no competing interests.

\section{Funding:}

The authors received no external funding for this study.

\section{Authors' contributions:}

DP performed the cytokine examination of the saliva, and was a major contributor in writing the manuscript.

YB analyzed and interpreted the patient data regarding the nephrotic syndrome

DL collected patient's data

YK analyzed the patient's data

NB collected patient's data

MD analyzed and interpreted the patient data regarding the nephrotic syndrome and was a major contributor in writing the manuscript

ED made substantial contributions to the conception and design of the work and was a major contributor in writing the manuscript

All the authors read and approved the final manuscript.

\section{References}

1. Lennon R, Watson L, Webb NJA. Nephrotic syndrome in children. Paediatrics and Child Health. 2010;20:36-42.

2. Trautmann A, Schnaidt S, Lipska-Zi冈tkiewicz BS, Bodria M, Ozaltin F, Emma F, et al. Long-term outcome of steroid-resistant nephrotic syndrome in children. J Am Soc Nephrol. 2017;28:3055-65.

3. Liu ID, Willis NS, Craig JC, Hodson EM. Interventions for idiopathic steroid-resistant nephrotic syndrome in children. Cochrane database Syst Rev. 2019;2019.

4. Bandhakavi S, Stone MD, Onsongo G, Van Riper SK, Griffin TJ. A dynamic range compression and three-dimensional peptide fractionation analysis platform expands proteome coverage and the diagnostic potential of whole saliva. J Proteome Res. 2009;8:5590-600. 
5. Xiao H, Zhang L, Zhou H, Lee JM, Garon EB, Wong DTW. Proteomic analysis of human saliva from lung cancer patients using two-dimensional difference gel electrophoresis and mass spectrometry. Mol Cell Proteomics. 2012;11:M111.012112.

6. Streckfus CF, Mayorga-Wark O, Arreola D, Edwards C, Bigler L, Dubinsky WP. Breast cancer related proteins are present in saliva and are modulated secondary to ductal carcinoma in situ of the breast. Cancer Invest. 2008;26:159-67.

7. Stott-Miller M, Houck JR, Lohavanichbutr P, Méndez E, Upton MP, Futran ND, et al. Tumor and salivary matrix metalloproteinase levels are strong diagnostic markers of oral squamous cell carcinoma. Cancer Epidemiol Biomarkers Prev. 2011;20:2628-36.

8. Rao P V., Reddy AP, Lu X, Dasari S, Krishnaprasad A, Biggs E, et al. Proteomic identification of salivary biomarkers of type-2 diabetes. J Proteome Res. 2009;8:239-45.

9. Baldini C, Giusti L, Ciregia F, Da Valle Y, Giacomelli C, Donadio E, et al. Proteomic analysis of saliva: a unique tool to distinguish primary Sjögren's syndrome from secondary Sjögren's syndrome and other sicca syndromes. Arthritis Res Ther. 2011;13:R194.

10. van Leeuwen S, Proctor GB, Potting C, Ten Hoopen S, van Groningen L, Bronkhorst EM, et al. Early salivary changes in multiple myeloma patients undergoing autologous HSCT. Oral Dis. 2018;24:972-82.

11. Pay JB, Shaw AM. Towards salivary C-reactive protein as a viable biomarker of systemic inflammation. Clin Biochem. 2019;68:1-8.

12. Hicks SD, Ignacio C, Gentile K, Middleton FA. Salivary miRNA profiles identify children with autism spectrum disorder, correlate with adaptive behavior, and implicate ASD candidate genes involved in neurodevelopment. BMC Pediatr. 2016;16:52.

13. Davidovich E, Aframian DJ, Shapira J, Peretz B. A comparison of the sialochemistry, oral pH, and oral health status of down syndrome children to healthy children. Int J Paediatr Dent. 2010;20:235-41.

14. Campbell H, Amirthalingam G, Fry NK, Litt D, Harrison TG, Wagner K, et al. Oral fluid testing for pertussis, England and wales, june 2007-august 2009. Emerg Infect Dis. 2014;20:968-75.

15. Klein Kremer A, Kuzminsky E, Bentur L, Nagler RM. Salivary and serum analysis in children diagnosed with pneumonia. Pediatr Pulmonol. 2014;49:569-73.

16. Blair J, Lancaster G, Titman A, Peak M, Newlands P, Collingwood C, et al. Early morning salivary cortisol and cortisone, and adrenal responses to a simplified low-dose short Synacthen test in children with asthma. Clin Endocrinol (Oxf). 2014;80:376-83.

17. Hogg RJ, Portman RJ, Milliner D, Lemley K V., Eddy A, Ingelfinger J. Evaluation and management of proteinuria and nephrotic syndrome in children: Recommendations from a pediatric nephrology panel established at the National Kidney Foundation Conference on Proteinuria, Albuminuria, Risk, Assessment, Detection, and Elimination (PARADE). Pediatrics. 2000;105:1242-9.

18. Guimarães FTL, Melo GEBA de, Cordeiro TM, Feracin V, Vieira ER, Pereira W de F, et al. T-lymphocyte-expressing inflammatory cytokines underlie persistence of proteinuria in children with idiopathic nephrotic syndrome. J Pediatr (Rio J). 94:546-53. doi:10.1016/j.jped.2017.08.005.

19. Barbaux S, Niaudet P, Gubler MC, Grünfeld JP, Jaubert F, Kuttenn F, et al. Donor splice-site mutations in WT1 are responsible for Frasier syndrome. Nat Genet. 1997;17:467-70.

20. Benzing T. Signaling at the slit diaphragm. J Am Soc Nephrol. 2004;15:1382-91. doi:10.1097/01.asn.0000130167.30769.55.

21. Kemper MJ, Wolf G, Müller-Wiefel DE. Transmission of glomerular permeability factor from a mother to her child. N Engl J Med. 2001;344:386-7.

22. Kang HG, Seo H, Lim JH, Kim J II, Han KH, Park HW, et al. Markers of disease and steroid responsiveness in paediatric idiopathic nephrotic syndrome: Whole-transcriptome sequencing of peripheral blood mononuclear cells. J Int Med Res. 2017;45:948-63.

\section{Figures}



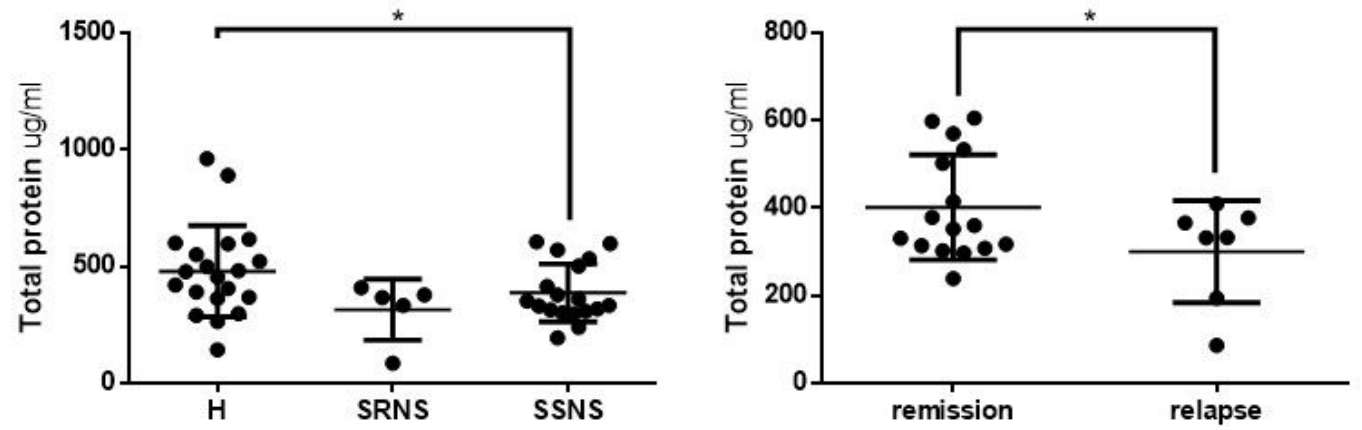

Figure 1

Total protein levels from the saliva of children with nephrotic syndrome and healthy controls. Samples from children with nephrotic syndrome were classified according to steroid-resistant nephrotic syndrome (SRNS) and steroid-sensitive nephrotic syndrome (SSNS); and according to the remission and relapse states. Total protein levels were quantified by a bicinchoninic acid assay. The values are presented as means and SD. * represents a statistically significant difference between the groups.
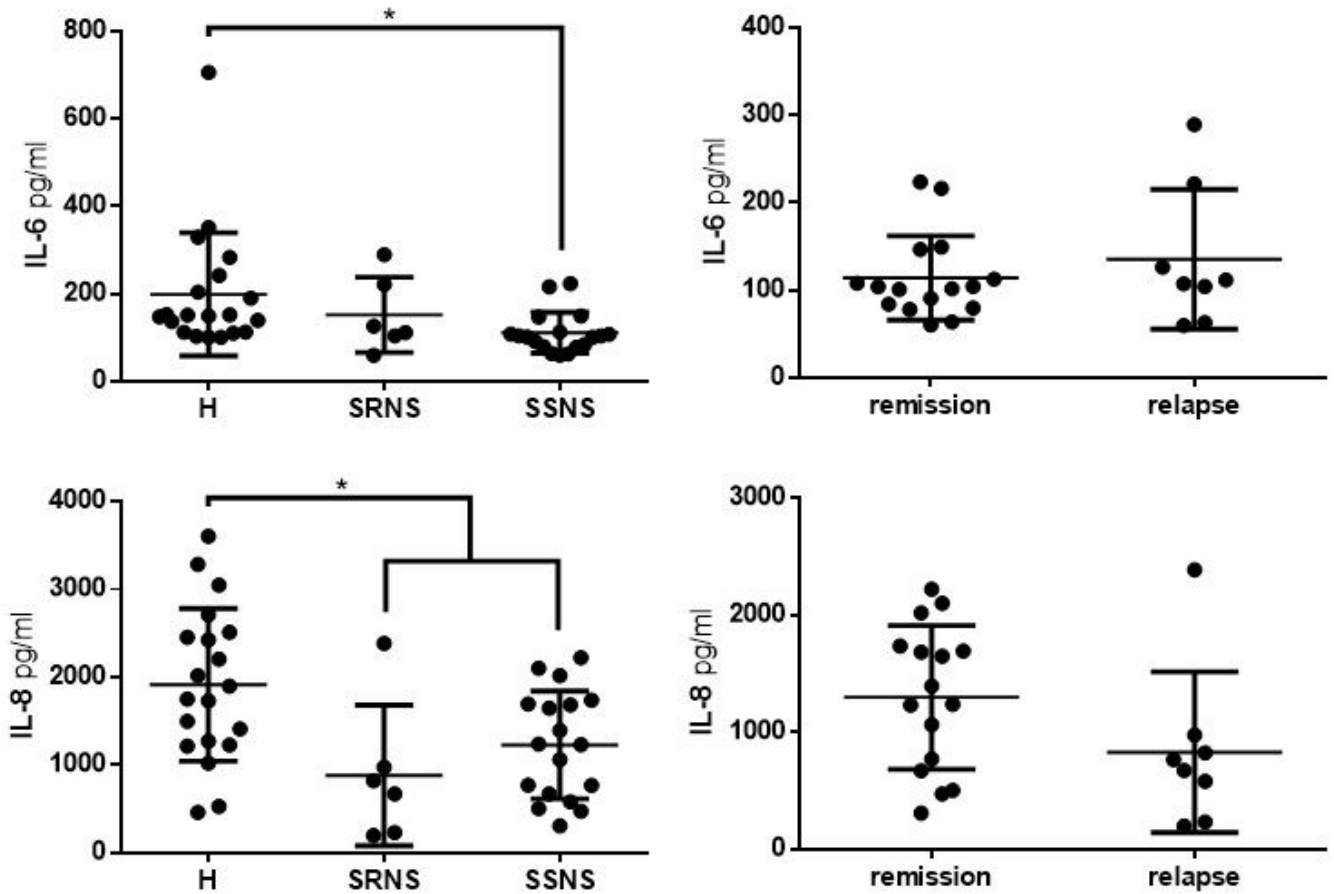

Figure 2 
Levels of IL-6 and IL-8 from the saliva of children with nephrotic syndrome and healthy controls. Samples from children with nephrotic syndrome were classified according to steroid-resistant nephrotic syndrome (SRNS) and steroid-sensitive nephrotic syndrome (SSNS); and according to the remission and relapse states. Levels of IL- 6 and IL- 8 were quantified by ELISA. The values are presented as means and SD. * represents a statistically significant difference between the groups.
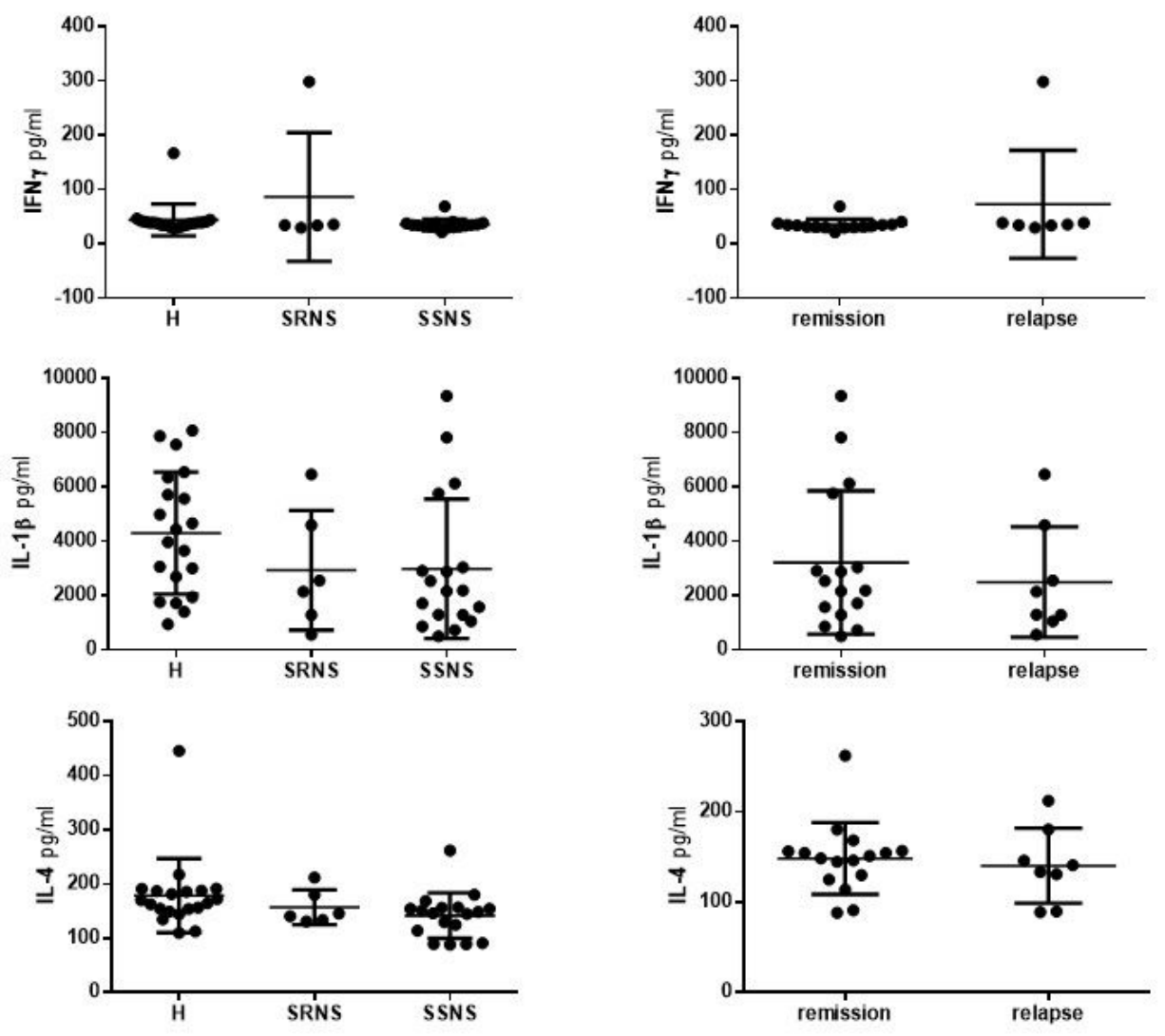

Figure 3

Levels of IL1 $\beta$, IFNy and IL-4 from the saliva of children with nephrotic syndrome and healthy controls. Samples from children with nephrotic syndrome were classified according to steroid-resistant nephrotic syndrome (SRNS) and steroid-sensitive nephrotic syndrome (SSNS); and according to the remission and relapse states. Levels of IL1 $\beta$, IFNY and IL-4 were quantified by ELISA. The values are presented as means and SD. * represents statistically a significant difference between the groups. 